PETER GROOTENBOER, GREGOR LOMAS, \& NAOMI INGRAM

\title{
THE AFFECTIVE DOMAIN AND MATHEMATICS EDUCATION
}

This chapter examines Australasian research in the affective domain. While this domain during this review period has continued to be dominated by a focus on beliefs, there is more research emerging in the areas of self-concept, identity, motivation, and engagement. There remains however a lack of theorising in aspects of the domain. Methodologically, while there has been an increase in mixed methods studies, there has been little change since the last review. With some exceptions, only a limited range of methodological instruments has been used. Data is still primarily self-reported rather than observational and this issue remains an aspect to be addressed in future research.

Key words: affective domain, beliefs, attitudes, emotions, identity

This is the second chapter on affective issues to appear in MERGA reviews of research in mathematics education and as such reflects the ongoing importance of affective issues to the mathematics education research community. The first such chapter (Schuck \& Grootenboer, 2004) noted a continuing move away from studies on attitudes to projects on beliefs and the consideration of a broader range of affective aspects. This broadening of areas of interest in exploring affect in mathematics education was reflective of worldwide trends. This is evidenced by significant recent publications such as: the seminal book edited by Leder, Pehkonen and Törner (2002) on beliefs in mathematics education; a special issue of the Mathematics Education Research Journal (August, 2005) whose editorial gave a brief overview of the previous 10 years of MERGA related research in the affective domain; a chapter in the Handbook of Research in the Psychology of Mathematics Education by Leder and Forgasz (2006) that discussed, among other matters, developments in the use of different methodological approaches and the potential of new technologies; and a Special Issue of Educational Studies in Mathematics (October, 2006) where a series of papers employed six complimentary theoretical frameworks to examine affective issues with a particular emphasis on the place of emotion in the affective domain.

The evolution of interest in the affective domain in mathematics education from considerations of attitudes and anxiety in the 1960s and 1970s, to a focus on the relationship between affect and cognition in problem solving, and gender, in the 1980s, and to McLeod's (1992) identification of the three affective concepts -

H. Forgasz, A. Barkatsas, A. Bishop, B. Clarke, S. Keast, W-T. Seah, P. Sullivan, \& S. Willis (eds.), Research in Mathematics Education in Australasia 2004-2007, xx-yy.

(C) 2008 Sense Publishers. All rights reserved. 
belief, attitudes and emotions - and the later addition of a fourth - values (sometimes including ethics and morals), are discussed in Zan, Brown, Evans and Hannula (2006). They state that arising from this history are two main trends in current research on affect: the development of theoretical/conceptual frameworks and of the development of new methodological instruments. In contrast to these trends, Leder and Grootenboer (2005) noted the overall lack of theorising and the limited range of methodological instruments used in Australasian research and presented a theoretical model of the relationships between the four concepts (see Figure 1) as a starting point in theorising the relationship between aspects of the affective domain.

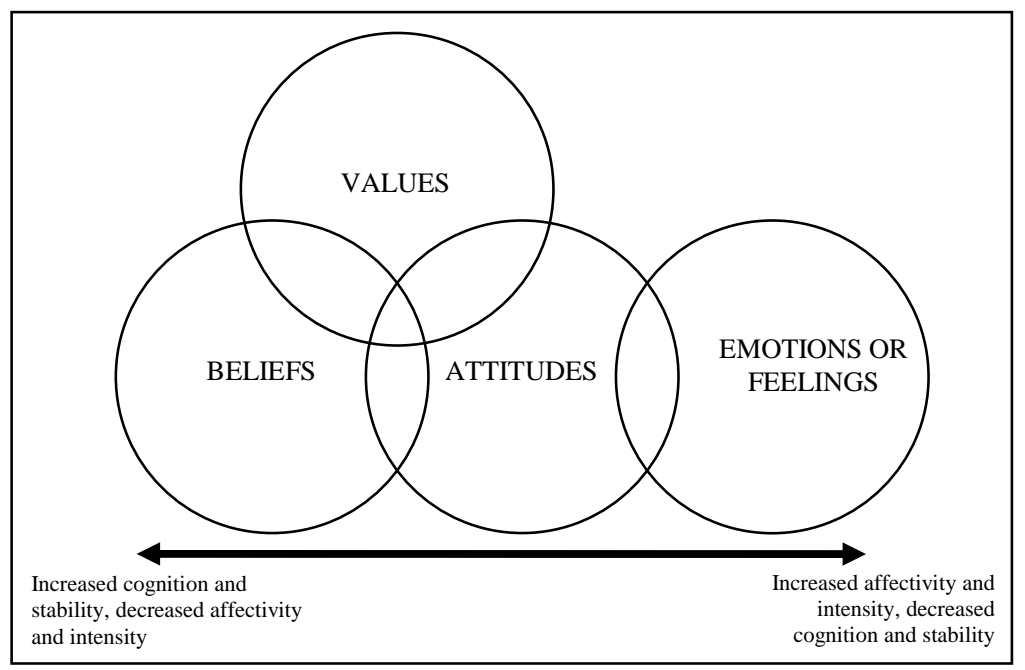

Figure 1. The affective domain (Leder \& Grootenboer, 2005)

Parallelling the global situation reported by Zan, Brown, Evans and Hannula (2006), Leder and Grootenboer (2005) reported a predominance of belief studies, a diminishing number of studies on attitudes, a small number of studies on 'emotions, feelings, attributions and motivation' (p. 3) and a few on values.

Given the relative paucity of work in Australasia on clarifying concepts and the development of theoretical frameworks, there has been little evolution of definitions of the four key aspects of affect considered in the last review chapter (Schuck \& Grootenboer, 2004). While the positions taken there are used in this chapter, Figure 1 captures a sense of a more holistic view of the affect domain as a continuum (McLeod, 1992) and its inclusion of the cognitive while delineating the four generally acknowledged concepts within affect - beliefs, attitudes, emotions and values. 
Beliefs are positions held by individuals that they feel to be true and their nature cannot be directly observed but must be inferred from actions. Although there are a variety of definitions of attitudes the common elements to these definitions are that attitudes are learnt and are evident in responses to a situation or object, and are seen as positive or negative. Emotions or feelings are described in terms of their transitory and unstable nature arising as an affective response to particular events/contexts whereas values are seen as criteria by which choices or assessments, in terms of desired/desirable outcomes or behaviours, are made (Schuck \& Grootenboer, 2004). The first three of these will be discussed, as will be self-concept/identity and engagement as in the previous review chapter. Following this, certain methodological aspects will be considered.

The following sections consider Australasian mathematics education research on the affective domain, except for work on values which is addressed in chapter $\mathrm{XXX}$ of this book, as outlined above.

\section{TOPICS/FINDINGS}

In the broad area of affect in mathematics education, research has focussed on a number of particular aspects, but about half of the studies have centred on beliefs. Other affective aspects that have been prevalent include attitudes, emotions, identity and engagement (and values).

\section{Beliefs}

The strong focus on beliefs is a continuing trend as was highlighted by Schuck and Grootenboer (2004) in the previous MERGA review. The studies published in the period 2004-2007 have again been mostly undertaken with teachers as their participants with many exploring the relationship between beliefs and practice. Two Australian writers, who have regularly addressed this area both on their own, and in conjunction with others, are Anderson (2005) and Beswick (2005a, 2005b, 2007).

Anderson (2005) (often with White \& Sullivan, 2004, 2005) reported on her work with primary school teachers in New South Wales where she explored the relationship between the teachers' problem solving teaching approaches and their beliefs about the role of problem solving in mathematics. Significantly, Anderson, Sullivan and White (2005) built on a range of earlier work to theorise and model the relationship between teachers' beliefs and practices for problem solving. After collecting data through a range of methods they developed and refined their model so that it included the significant influence of the social context. A particular feature of Anderson, Sullivan and White's report was the authors' attention to theorising, setting this report apart from many other, often largely descriptive, reports on teachers' beliefs.

Beswick is another author who has reported extensively and for an extended period of time on beliefs (Beswick, 2005a, 2005b, 2007; Beswick, Watson, \& Brown, 2006), focussing primarily on secondary teachers. Amongst other findings, 
she identified nine beliefs held by secondary teachers about the nature of mathematics, mathematics learning and the role of the teacher. Furthermore, | Beswick noted some associations between particular clusters of beliefs and the classroom environment, but also highlighted that these relationships were complex and contextually bound. Other studies on teachers' beliefs include: Barkatsas and Malone's (2005) exploration of the beliefs Greek mathematics teachers and the relationship with their practice; McDonough and Clarke's (2005) inquiry into changes in the practices and beliefs of primary teachers involved with a numeracy professional development program; Nisbet and Grimbeek's (2004) quantitative review of primary teachers' beliefs about compulsory numeracy testing; Perry, Way, Southwell, White and Pattison's (2005) examination of the relationship between preservice teachers' beliefs and mathematical achievement; Prescott and Cavanagh's (2006) qualitative study into preservice secondary teachers beliefs about effective mathematics teaching; and, Scott's (2005) mixed method investigation and modelling of preservice primary teachers beliefs and intentions about mathematics education.

Studies into students' beliefs about mathematics and mathematics learning have been less frequent than ones on teachers' beliefs, but nevertheless, there has been some work done in this area. A focussed area for this study has been the University of Waikato (New Zealand) where Taylor, Hawera and Young-Loveridge (2005), Young-Loveridge and Taylor (2005), and Young-Loveridge, Taylor, Sharma and Hawera (2006) have reported often on primary students' beliefs about mathematics learning, particularly in the context of the New Zealand Numeracy Project. Various reports showed that many students had clear expectations about the teachers' role in teaching them mathematics and deep-seated views about mathematics, and these influenced their learning.

In 2007 there were also reports from Anderson (2007), Grootenboer (2007), Ng and Stillman (2007), Pierce, Stacey and Barkatsas (2007), and Sullivan and McDonough (2007) on the development of theory-based quantitative instruments to measure student's affective responses to mathematics. While at this stage the findings from the use of these instruments are limited, it is timely that some more robust and rigorous scales are developed.

\section{Attitudes and Emotions}

In the period 2004 to 2007 there were only a few reports of research that focussed specifically on attitudes and emotions. Pierce and Stacey (2006) reported on a qualitative study that explored the improvement of students' attitudes to mathematics through association with simple pleasures from real world contexts. They found that real world contexts appeared to lead to improved student attitudes to mathematics, but they cautioned that this was due to superficial pleasures rather than substantive mathematics. These authors also worked with Barkatsas (Pierce, Stacey, \& Barkatsas, 2007) to develop the Mathematics and Technology Attitudes Scale (MTAS) that monitored students' attitudes to learning mathematics with technology. In this study they reported some small gender differences between the 
attitudes and confidence of the boys and girls related to learning mathematics with technology.

In terms of students' attitudes to learning a particular aspect of mathematics, Norton and Irvin (2007) reported on a classroom intervention which was designed to develop students' positive perceptions of their ability to learn algebra. The sixweek intervention was based around a selection of activities designed to enable students to make connections between materials, verbal language, and symbolic language. The study found that the students valued the instructional discourse much more than they did their normal mathematics learning experience and had an increased confidence in their capacity to understand algebra.

Another attitudinal study focussed on secondary mathematics teachers' attitudes to a range of alternative assessment methods (Watt, 2005). In short, Watt found that these teachers were generally satisfied with traditional tests as valid measures of student achievement and they did not favour alternative assessments as they were seen as too subjective.

Studies that centred particularly on emotional aspects of learning mathematics were rather scarce. Hawera (2004) reported on a tertiary course designed to address the feelings of some mathematically anxious preservice primary teachers. She found that by creating a safe learning environment and by building the course around social constructivist principles, the participants were able to go some way to addressing their mathematical anxiety. Frankcom's (2006) thesis examined mathematics anxiety and self efficacy in preservice primary teachers and found, as expected, that these were closely negatively correlated but that, unexpectedly, success with mastery experiences in their mathematics education courses did not reduce anxiety or increase self efficacy significantly. In Shannon's (2004) case study with one senior secondary school girl, she found that there were a range of factors that were often not necessarily mathematical, that caused the student to dislike and avoid participation in mathematics.

\section{Other Affective Aspects}

Other studies related to the affective domain emerging amongst the MERGA community focus on identity and engagement. Walshaw (2004a, 2004b) and Klein (2004) focussed on the construction of identity with preservice teachers. They both highlighted the complexity of identity development and the many discourses that influence the process. A 2006 symposium at MERGA 2006 on researching identity in mathematics education provided a general overview (Grootenboer, Smith, \& Lowrie, 2006), and then explored the topic from a range of perspectives including Bourdieuian (Zevenbergen, 2006), Wenger's social theory of learning (Smith, 2006), and feminist poststructuralism (Letts, 2006). The symposium was not grounded in empirical research, but rather it gave some theoretical under-pinning to work that may emerge in this area. Grootenboer and Zevenbergen (2007) and Ingram (2007) have presented subsequent papers that further explore identity in empirical studies on mathematical learning and secondary students' affective responses to mathematics respectively. 
Motivation and engagement have been explored by Sullivan, McDonough and their colleagues (Sullivan \& McDonough, 2007; Sullivan, McDonough, \& Turner Harrison, 2004; Sullivan, Tobias, \& McDonough, 2006). Their large scale and continuing work has already produced a number of findings including the role peer pressure and classroom culture can play in inhibiting students' learning opportunities in mathematics. Cretchley (2005) examined engagement through lecture attendance in a tertiary context and found that there was a relationship between participation and mathematics performance.

\section{Critique of the Topics/Findings}

In the preceding section we have provided a brief and concise summary of much of the Australasian research that has been reported on the affective domain in mathematics education in the period 2004-2007. While each report appears to have individual merit, there are some themes and issues that are worth noting. This critique is not so much about individual reports or studies, but rather about the topics, findings and directions of the body of research in this area.

In the period 2004-2007 a significant proportion of the reports have focussed on beliefs; a trend that has continued since the last review of research in this area (Schuck \& Grootenboer, 2004). There is a sense that some of the research has not so much built on the previous work but is largely more of the same. Indeed, many are largely descriptive studies of teachers' beliefs, and lack any significant theorising. It seems that in other parts of the world they are beginning to consider the theoretical foundations of research into beliefs and other affective aspects (e.g., Zan, Brown, Evans, \& Hannula, 2006), and it is time for a greater theorising about the general findings that are, seemingly, being consistently reported in Australasia.

Many of the reports reviewed focus on a particular aspect of the affective domain and this has given some illumination on these dimensions in mathematics teaching and learning. However, due to the complex nature of the affective domain, and the difficulties in clearly defining its various components, it would be valuable to see affectivity explored in a more holistic manner. Similarly, there appears to be only a few studies that look at the relationship between affectivity and cognition and achievement (e.g., Watson, Beswick, Brown, \& Callingham, 2007). That said, Walshaw and Cabral (2005) contend that there are a number of studies into affective and cognitive aspects of mathematics learning that are grounded in theories of discursive practice, embodiment, somatic markers, neuroscience, representation and situated practice, although these are largely undertaken outside of Australasia (see Zan, Brown, Evans, \& Hannula, 2006). Now that there appears to be a greater understanding of the affective domain and its components, it is time for a more focussed research agenda that examines these relationships. The emerging focus on identity may well provide an avenue for such research. 


\section{METHODOLOGICAL ISSUES}

In this section we have focussed on methodological issues because of their importance when researching the affective domain in mathematics education. As understanding has grown of the complex nature of mathematics education, multiple perspectives and new approaches to research methodologies and paradigms have become valued. This is particularly true for the affective domain, which has unique methodological issues and limitations because of its complexity as evidenced by Bragg's (2007) discussion of attempts to reconcile contradictory indicators arising from quantitative and qualitative data. Also significant are the ethical issues surrounding its highly personal nature and the high level of inference required. In their review of affective literature, Leder and Forgasz (2006) stated "affect can not be measured directly but needs to be inferred from the way an individual behaves or responds to specifically designed instruments, cues, or situations" (p. 404). This reliance on inference can limit affective research to "beliefs, attitudes and feelings that participants are willing and able to share in either a verbal or written form" (Schuck \& Grootenboer, 2004, p. 12), creating a high proportion of self-reporting data collection methods (Leder \& Forgasz, 2006).

Anthony (2004) in her review of trends in mathematics education, commented that grouping research papers by methodology was "fraught with difficulty" (p. 6) because of a multiplicity of descriptors used by researchers. This was reflected in the Australasian literature during the current review period. Philosophical assumptions and methodological frameworks were sometimes absent and only the methods and instruments used described. There are many reasons why this may be the case including the limited space available in many contexts, but, "metaphorically, unarticulated philosophical perspectives are like an unlighted room ... one is likely to stumble over objects and to misunderstand the nature of the rooms within which one is stumbling around" (Maykut \& Morehouse, 1994, p. 22).

In this research period, excluding a small number of non-empirical position and review papers, about a quarter of the studies were quantitative (26\%) and there were about equal numbers of qualitative (38\%) and mixed method studies (36\%); the increase in mixed method studies reflecting general research trends (Creswell, 2003). Mixed method studies include a simultaneous or sequential collection of elements of qualitative and quantitative methods in their design (Creswell, 2003; Lankshear \& Knobel, 2004). Research in this domain can perhaps be better seen as lying on a continuum between qualitative and quantitative. There are a number of studies in this research period that tend to be more qualitative. They are qualitative in nature but have varying levels of simple numerical analysis, which help clarify patterns or can be used for descriptive or illustrative purposes (Lundy Dobbert \& Kurth-Schai, 1992). McDonough and Clarke (2005), for example, in investigating change in teachers' beliefs and practice as a result of professional development in the Early Numeracy Research Project in Victoria, used some quantification in comparing the entry and exit questionnaires by using tables with frequencies of themes and a simple t-test to show differences in beliefs about the nature of mathematics, the role of the teacher, and attitude and confidence in teaching 
mathematics. Barkatsas and Malone (2005) is an example of a mixed method design that tends towards the quantitative. They used a sequential explanatory strategy of inquiry when they initially investigated 465 Greek mathematics teachers' beliefs through a quantitative survey, and then explored the links between these beliefs and classroom practice through a case study of one secondary school mathematics teacher. The qualitative data from the teacher was integrated into the overall analysis to help explain and interpret the findings of the larger quantitative study.

The last four yearly review stated a need for more classroom-based research using observational methods in primary and secondary classrooms (Schuck \& Grootenboer, 2004). While this review period indicates that a better balance in the affective literature has been achieved with more studies researching, in particular, secondary students, this research can not necessarily be considered classroombased. A large proportion of the student-centred studies were done through interviews and surveys. The most frequent instruments were Likert-scale or openended questionnaires and semi-structured interviews. Other methods used were classroom observations (e.g., Seah, 2004), the collection of assessment information (Cretchley, 2005; Seah, 2004), weekly conferences (Caswell \& Nisbet, 2005), journals (Hawera, 2004; Wilson \& Thornton, 2005, 2006), task-related interviews or teaching conversations (Sullivan, Tobias, \& McDonough, 2006), and artefact collection such as student work samples, written reflections, and enrolment information (Brady, 2007; Parnell, 2005; Williams, 2006).

Smith (2006) explored the innovative methodology of self-study through narrative inquiry using as a context a preservice mathematics curriculum subject of which she was the teacher. She found narrative inquiry allowed her "identities as classroom teacher, teacher educator, learner, and researcher to come together" (p. 477) enabling her to monitor her own journey, become a co-learner and therefore, maximise generative learning. Later in the review period Bailey (2007) also employed the use of narrative inquiry to pursue and change previously unknown personal beliefs about learning mathematics. Anderson (2005) used a Personal Journey Graph as an instrument in a case study that followed one teacher through the implementation of the New Zealand Intermediate Numeracy Project. A narrative framework was used and data gathered about changing attitudes and beliefs, mathematical and pedagogical content knowledge, and knowledge of student learning in numeracy. The Personal Journey Graph was drawn to reflect the teacher's "opinion of her ability to implement the approaches consistent with the Numeracy Project in her mathematics classroom" (p. 98). The teacher was asked to draw a curve that represented her implementation ability over time as low, medium or high. She was given the opportunity to reflect on and make changes to her graph at the end of the following year. The graph showed the teacher's initial confidence waning and then rapidly increasing in the latter half of the year allowing a unique insight into the teacher's reflections of her journey. This instrument was also being used by Ingram (2007) to understand the affective development of secondary school students through exploring their mathematical identities. 
Leder and Forgasz (2006) explored other methodological possibilities available now with technological advances such as mobile phones and the conferencing facilities of the internet. They outlined the Experience Sampling Method (ESM), which allow self-reports of mental processes by using a signal as a trigger between five and seven times per day (Leder \& Forgasz, 2006). Participants chart their activities, and their reactions to and beliefs about those activities allowing a less intrusive way of capturing rich and comprehensive data. Forgasz and Leder (2006) used ESM to collect contextualised information to explore the work patterns and factors associated with stress in experienced and novice secondary mathematics teachers. Over a one-week period, the daily lives of 14 teachers were tracked using mobile phone text-messaging as a signal and data collected on their activities and their reactions to those activities. Four of the teachers were then interviewed. The study found that teachers' work-related activities extended beyond work hours and, while teaching mathematics was more likely to be the cause of stress for novice teachers, experienced teachers experienced high engagement and pleasure in the task of teaching mathematics, and were more likely to find administration work a stressor.

The consistencies and inconsistencies between teachers' professed and attributed beliefs remains a major topic of study. However, there have been few advances made to research designs, data collection, and data analysis methods. Speer (2005) cautions that reported inconsistencies in this field of research may be actually the consequence of methodological issues, specifically a lack of shared understanding among researchers and teachers about what descriptive terms mean, and a consequence of a lack of coordination between data on beliefs and practices. Furthermore Speer (2005) contends "that it is inappropriate to classify any data on beliefs as purely professed. All claims about teachers' beliefs are, to greater or lesser extents, attributed to teachers by researchers" (Speer, 2005, p. 362). Anderson, Sullivan, and White $(2004,2005)$ go some way to addressing these concerns. They investigated the problem-solving beliefs and practices of 162 primary teachers through a mixed method study using surveys, semi-structured interviews, which used the survey responses as a starting point, and classroom observations of two of the teachers. The authors recognised the possibilities of misinterpretation in the survey questions and provided specific examples for the teachers to illustrate the terminology.

Longitudinal studies are an important way of studying affect, allowing understanding about what mathematical experiences the students have throughout their education that led to the development of their affective views (Schuck \& Grootenboer, 2004). There were few studies in the review period, which were explicitly called longitudinal. Lomas (2004) in his doctoral research examined the perceptions of a primary preservice teacher cohort over the three year period of their preservice teacher education degree. This tracked the level of alignment of a 'reform' agenda promoted by lecturers with its acceptance by the preservice teachers. The findings show, over the three-year period of the study, high levels of alignment with the pedagogical aspects of reform but significantly lower levels with emancipatory aspects and only minor incremental change in students' 
alignment in both aspects. Many of the longitudinal studies in the review period (2004-2007) were reported in parts. The reasons for this are perhaps because research is being published as it is being analysed particularly in longitudinal studies relating to doctoral research or because of the space limitations in journal and conference proceedings. This can lead to problems when the general and methodological background for a paper is not fully presented due to their inclusion in an earlier one so the paper does not completely stand-alone.

There is also a relative absence of action research or interventionist type research in this period. The wealth of descriptive studies over the last decade have provided a rich awareness of affective concerns in mathematics education, and it is now time to undertake further studies that seek to not only report on, but also move forward, on some of these concerns. As we continue to improve our knowledge about the affective domain, this seems an important strategy for researchers to adopt, literally putting knowledge into practice.

In the last review, Schuck and Grootenboer (2004) questioned the disproportionate number of studies that involved preservice and inservice teachers, and wondered if this was because these groups were more readily available to the current field of researchers, often preservice teacher educators. This finding appears to be different from Anthony's (2004) review, which found that students were the main focus, although it may be that preservice teachers were considered here to be students. Anthony (2004) also remarked that there had been a noticeable decrease in the proportion of papers that relate to the wider tertiary sector. In this review period there have been several studies in the affective literature published about tertiary students, in particular with a focus on technology (e.g., Berger \& Cretchley, 2005). However, there are still gaps in studies on tertiary mathematics lecturers and a noticeable (now glaring) gap in any research in the early childhood sector. There is also no research that concerns vocational education participants, the community, or parents. This is consistent with the last review (Schuck \& Grootenboer, 2004) and also reflects Leder and Forgasz's (2006) comment that there has been little examination of general societal beliefs about mathematics or the community's concern with affectivity.

\section{CONCLUDING COMMENTS}

In the 2004 review a recommendation for a greater focus on school students' affectivity was made. Over the last 4 years, although there has been an increase in the number research reports dealing with school student perspectives, with a predominance of secondary focussed studies, preservice teacher and classroom teacher studies continue to dominate. This continues the trend reported by Leder and Grootenboer (2005) and adds weight to their call for more work with primary children and in early childhood.

While links between beliefs and practice continue to be a major area of interest, few studies advance any theoretical considerations that might underpin causal relationships between the two. Implications in studies are rarely developed beyond a local frame of reference and indeed the testing or development of theoretical 
frameworks is largely absent. The need for theory development to underpin research is apparent elsewhere in the world and needs to be a feature of Australasian affect research in the near future.

Changes in methodological approaches have seen an increase in mixed method studies with roughly equal numbers of qualitative, quantitative and mixed method studies being represented. However, the actual extent of this change is difficult to determine due to the ongoing reporting of some larger studies in small segments, and with a variety of authors, which leads to multiple counts of some approaches. This is further compounded by apparent variation in what is understood by mixed methods; in some studies labelled mixed methods by the researchers, the reviewers held a different view. Alongside this trend toward mixed methods studies with multiple data sources has been the continued use of familiar data collection methods. Indeed, the use of new types of instruments has been relatively limited. The methods of data collection used remain predominantly that of self-reporting via survey and interview, with classroom observation being largely absent. This situation tends to restrict affect research to individual and group perceptions. If belief/practice investigations are to move to more fertile ground then it is important that observational data of teachers and students in classroom environments become an integral part of research projects.

\section{REFERENCES}

Anderson, J. (2005). I didn't know what I didn't know: A case study of growth in teacher knowledge within the Intermediate Numeracy Project. In P. Clarkson, A. Downton, D. Gronn, M. Horne, A. McDonough, R. Pierce \& A. Roche (Eds.), Building connections: Research, theory and practice (Proceedings of the 28th annual conference of the Mathematics Education Group of Australasia, Melbourne, Vol. 1, pp. 97-104). Sydney: MERGA.

Anderson, J., Sullivan, P., \& White, P. (2004). The influence of perceived constraints on teachers' problem-solving beliefs and practices. In I. Putt, R. Faragher \& M. McLean (Eds.), Mathematics education for the third millennium: Towards 2010 (Proceedings of the 27th annual conference of the Mathematics Education Research Group of Australasia, Townsville, Vol. 1, pp. 39-46). Sydney: MERGA.

Anderson, J., Sullivan, P., \& White, P. (2005). Using a schematic model to represent influences on, and relationships between, teachers' problem-solving beliefs and practices. Mathematics Education Research Journal, 17(2), 9-38.

Anderson, V. (2007). An online survey to assess student anxiety and attitude response to six different mathematical problems. In J. Watson \& K. Beswick (Eds.), Mathematics: Essential research, essential practice (Proceedings of the 30th annual conference of the Mathematics Education Research Group of Australasia, Tasmania, Vol. 1, pp. 93-102). Adelaide: MERGA.

Anthony, G. (2004). MERGA: A community of practice. In I. Putt, R. Faragher \& M. McLean (Eds.), Mathematics education for the third millennium: Towards 2010 (Proceedings of the 27th annual conference of the Mathematics Education Research Group of Australasia, Townsville, Vol. 1, pp. 215). Sydney: MERGA.

Bailey, J. (2007). Mathematical investigations: A primary teacher educator's narrative journey of professional awareness. In J. Watson \& K. Beswick (Eds.), Mathematics: Essential research, essential practice (Proceedings of the 30th annual conference of the Mathematics Education Research Group of Australasia, Tasmania, Vol. 1, pp. 103-112). Adelaide: MERGA. 
GROOTENBOER, LOMAS, \& INGRAM

Barkatsas, A., \& Malone, J. (2005). A typology of mathematics teachers' beliefs about teaching and learning mathematics and instructional practices. Mathematics Education Research Journal, 17(2), 69-90.

Berger, M., \& Cretchley, P. (2005). Technology and mathematics learning at university level: A South African perspective. African Journal of Research in Mathematics, Science, and Technology Education, 9(2), 97-108.

Beswick, K. (2005a). The beliefs/practice connection in broadly defined contexts. Mathematics Education Research Journal, 17(2), 39-68.

Beswick, K. (2005b). It depends on the students: Influencing teachers' beliefs about the ends and means of numeracy teaching. In P. Clarkson, A. Downton, D. Gronn, M. Horne, A. McDonough, R. Pierce \& A. Roche (Eds.), Building connections: Research, theory and practice (Proceedings of the 28th annual conference of the Mathematics Education Group of Australasia, Melbourne, Vol. 1, pp. 137144). Sydney: MERGA.

Beswick, K. (2007). Teachers' beliefs that matter in secondary mathematics classrooms. Educational Studies in Mathematics, 65(1), 95-120.

Beswick, K., Watson, J., \& Brown, L. (2006). Teachers' confidence and beliefs about the ends and means of numeracy teaching. In P. Grootenboer, R. Zevenbergen \& M. Chinnappan (Eds.), Identities, cultures and learning spaces (Proceedings of the 29th annual conference of the Mathematics Education Research Group of Australasia, Canberra, Vol. 1, pp. 68-83). Adelaide: MERGA.

Brady, K. (2007). Imagined classrooms: Prospective primary teachers visualise their ideal mathematics classroom. In J. Watson \& K. Beswick (Eds.), Mathematics: Essential research, essential practice (Proceedings of the 30th annual conference of the Mathematics Education Research Group of Australasia, Tasmania, Vol. 1, pp. 143-152). Adelaide: MERGA.

Bragg, L. (2007). Students' conflicting attitudes towards games as a vehicle for learning mathematics: A methodological dilemma. Mathematics Education Research Journal, 19(1), pages?.

Caswell, R., \& Nisbet, S. (2005). Enhancing mathematical understanding through self-assessment and self-regulation of learning: The value of meta-awareness. In P. Clarkson, A. Downton, D. Gronn, M. Horne, A. McDonough, R. Pierce \& A. Roche (Eds.), Building connections: Research, theory and practice (Proceedings of the 28th annual conference of the Mathematics Education Group of Australasia, Melbourne, Vol. 1, pp. 209-216). Sydney: MERGA.

Creswell, J. (2003). Research design: Qualitative, quantitative, and mixed method approaches (2nd ed.). California: Sage Publications.

Cretchley, P. (2005). Mathematics and dumping lectures: Another perspective on the shift towards learner pragmatism. In M. Bulmer, H. McGillivray \& C. Varsavski (Eds.), Proceedings of the fifth Southern Hemisphere conference on undergraduate mathematics and statistics teaching and learning, Brisbane (Vol.?? pp.??). International Delta Steering Committee.

Forgasz, H., \& Leder, G. (2006). Work patterns and stressors. Australian Mathematics Teacher, 62(3), 36-40.

Frankcom, G. (2006). Maths anxiety in third year pre-service primary student teachers: Fact or fiction? Unpublished Masters thesis, University of Auckland.

Grootenboer, P. J. (2007). Measuring students' affective responses to mathematics and mathematics education. In C. S. Lim, S. Fatimah, G. Munirah, S. Hajar, M. Y. Hashimah, W. L. Gan \& T. Y. Hwa (Eds.), Meeting challenges of developing quality mathematics education culture (Proceedings of the 4th East Asia Regional Conference on Mathematics Education, pp. 273-280). Penang, Malaysia: Universiti Sains Malaysia.

Grootenboer, P. J., Smith, T., \& Lowrie, T. (2006). Researching identity in mathematics education: The lay of the land. In P. Grootenboer, R. Zevenbergen \& M. Chinnappan (Eds.), Identities, cultures and learning spaces (Proceedings of the 29th annual conference of the Mathematics Education Research Group of Australasia, Canberra, Vol. 2, pp. 612-615). Adelaide: MERGA.

Grootenboer, P. J., \& Zevenbergen, R. (2007). Identity and mathematics: Towards a theory of agency in coming to learn mathematics. In J. Watson \& K. Beswick (Eds.), Mathematics: Essential research, 
essential practice (Proceedings of the 30th annual conference of the Mathematics Education Research Group of Australasia, Tasmania, Vol. 1, pp. 335-344). Adelaide: MERGA.

Hawera, N. (2004). Addressing the needs of mathematically anxious preservice primary teachers. In I. Putt, R. Faragher \& M. McLean (Eds.), Mathematics education for the third millennium: Towards 2010 (Proceedings of the 27th annual conference of the Mathematics Education Research Group of Australasia, Townsville, Vol. 1, pp. 287-294). Sydney: MERGA.

Ingram, N. (2007). A story of a student fulfilling a role in the mathematics classroom. In J. Watson \& K. Beswick (Eds.), Mathematics: Essential research, essential practice (Proceedings of the 30th annual conference of the Mathematics Education Research Group of Australasia, Tasmania, pp. 450459). Adelaide: MERGA.

Klein, M. (2004). Preservice teacher education in mathematics: Thinking innovatively about innovation. In I. Putt, R. Faragher \& M. McLean (Eds.), Mathematics education for the third millennium: Towards 2010 (Proceedings of the 27th annual conference of the Mathematics Education Research Group of Australasia, Townsville, pp. 328-335). Sydney: MERGA.

Lankshear, C., \& Knobel, M. (2004). A handbook for teacher research: From design to implementation. England: Open University Press.

Leder, G., \& Forgasz, H. J. (2006). Affect and mathematics education. In A. Gutiérrez \& P. Boero (Eds.), Handbook of research on the psychology of mathematics education: Past, present and future (pp. 403-427). Rotterdam, The Netherlands: Sense Publishers.

Leder, G., \& Grootenboer, P. (2005). Affect and mathematics education. Mathematics Education Research Journal, 17(2), 1-8.

Leder, G., Pehkonen, E., \& Törner, G. (2002). Beliefs: A hidden variable in mathematics education? Dordrecht, The Netherlands: Kluwer Academic.

Letts, W. (2006). Bringing feminist poststructuralism to bear on [mathematics] teacher education. In P. Grootenboer, R. Zevenbergen \& M. Chinnappan (Eds.), Identities, cultures and learning spaces (Proceedings of the 29th annual conference of the Mathematics Education Research Group of Australasia, Canberra, pp. 623-627). Adelaide: MERGA.

Lomas, G. (2004). The relationship between mathematics educators' beliefs and their teaching practices. Unpublished Doctoral Thesis, Curtain University of Technology, Perth.

Lundy Dobbert, M., \& Kurth-Schai, R. (1992). Systematic ethnography: Towards an evolutionary science of education and culture. In The handbook of qualitative research in education. California: Academic Press, Inc.

Maykut, P., \& Morehouse, R. (1994). Beginning qualitative research: A philosophic and practical guide. London: The Falmer Press.

McDonough, A., \& Clarke, B. (2005). Professional development as a catalyst for changes in beliefs and practice: Perspectives from the Early Numeracy Research Project. In P. Clarkson, A. Downton, D. Gronn, M. Horne, A. McDonough, R. Pierce \& A. Roche (Eds.), Building connections: Research, theory and practice (Proceedings of the 28th annual conference of the Mathematics Education Group of Australasia, Melbourne, pp. 521-528). Sydney: MERGA.

McLeod, D. B. (1992). Research on affect in mathematics education: A reconceptualisation. In D. Grouws (Ed.), Handbook of research on mathematics teaching and learning (pp. 575-596). New York: NCTM and Macmillan.

Ng, K. E. D., \& Stillman, G. (2007). Interdisciplinary learning: Development of mathematical confidence, value, and the interconnectedness of mathematics scales. In J. Watson \& K. Beswick (Eds.), Mathematics: Essential research, essential practice (Proceedings of the 30th annual conference of the Mathematics Education Research Group of Australasia, Tasmania, pp. 533-542). Adelaide: MERGA.

Nisbet, S., \& Grimbeek, P. (2004). Primary teachers' beliefs and practices with respect to compulsory numeracy testing. In I. Putt, R. Faragher \& M. McLean (Eds.), Mathematics education for the third millennium: Towards 2010 (Proceedings of the 27th annual conference of the Mathematics Education Research Group of Australasia, Townsville, pp. 406-413). Sydney: MERGA. 
GROOTENBOER, LOMAS, \& INGRAM

Norton, S., \& Irvin, J. (2007). Developing positive attitudes towards algebra. In J. Watson \& K. Beswick (Eds.), Mathematics: Essential research, essential practice (Proceedings of the 30th annual conference of the Mathematics Education Research Group of Australasia, Tasmania, pp. 561-570). Adelaide: MERGA.

Parnell, S. M. (2005). Do student reflections increase undergraduate mathematics learning? In M. Bulmer, H. MacGillivray \& C. Varsavsky (Eds.), Proceedings of Kingfisher Delta '05, World Heritage Fraser Island, Queensland, Australia (pp. 95-102). Place published?? Publisher??

Perry, B., Way, J., Southwell, B., White, A. L., \& Pattison, J. (2005). Mathematical beliefs and achievement of pre-service primary teachers. In P. Clarkson, A. Downton, D. Gronn, M. Horne, A. McDonough, R. Pierce \& A. Roche (Eds.), Building connections: Research, theory and practice (Proceedings of the 28th annual conference of the Mathematics Education Group of Australasia, Melbourne, pp. 625-632). Sydney: MERGA.

Pierce, R., \& Stacey, K. (2006). Enhancing the image of mathematics by association with simple pleasures from real world contexts. Zentralblatt fur Didaktik der Mathematik, 38(3), 214-225.

Pierce, R., Stacey, K., \& Barkatsas, A. (2007). A scale for monitoring students' attitudes to learning mathematics with technology. Computers in Education, 48(2), 285-300.

Prescott, A., \& Cavanagh, M. (2006). An investigation of pre-service secondary mathematics teachers' beliefs as they begin their teacher training. In P. Grootenboer, R. Zevenbergen \& M. Chinnappan (Eds.), Identities, cultures and learning spaces (Proceedings of the 29th annual conference of the Mathematics Education Research Group of Australasia, Canberra, pp. 424-431). Adelaide: MERGA.

Schuck, S., \& Grootenboer, P. (2004). Affective issues in mathematics education. In B. Perry, C. Diezmann \& G. Anthony (Eds.), Review of mathematics education in Australasia 2000-2003 (pp. 53-74). Sydney: MERGA.

Scott, A. L. (2005). Preservice teachers' intentions to provide good examples and help children replicate them. In P. Clarkson, A. Downton, D. Gronn, M. Horne, A. McDonough, R. Pierce \& A. Roche (Eds.), Building connections: Research, theory and practice (Proceedings of the 28th annual conference of the Mathematics Education Group of Australasia, Melbourne, pp. 656-663). Sydney: MERGA.

Seah, W. T. (2004). Shifting the lens of inquiry into the socialisation of mathematics teachers: Nature of value differences. In I. Putt, R. Faragher \& M. McLean (Eds.), Mathematics education for the third millennium: Towards 2010 (Proceedings of the 27th annual conference of the Mathematics Education Research Group of Australasia, Townsville, pp. 501-508). Sydney: MERGA.

Shannon, F. (2004). Classics counts over calculus: A case study. In I. Putt, R. Faragher \& M. McLean (Eds.), Mathematics education for the third millennium: Towards 2010 (Proceedings of the 27th annual conference of the Mathematics Education Research Group of Australasia, Townsville, pp. 509-516). Sydney: MERGA.

Smith, T. (2006). Self-study through narrative inquiry: Fostering identity in mathematics teacher education. In P. Grootenboer, R. Zevenbergen \& M. Chinnappan (Eds.), Identities, cultures and learning spaces (Proceedings of the 29th annual conference of the Mathematics Education Research Group of Australasia, Canberra, pp. 471-478). Adelaide: MERGA.

Speer, N. M. (2005). Issues of methods and theory in the study of mathematics teachers' professed and attributed beliefs. Educational Studies in Mathematics, 58, 361-291.

Sullivan, P., \& McDonough, A. (2007). Eliciting positive student motivation for learning mathematics. In J. Watson \& K. Beswick (Eds.), Mathematics: Essential research, essential practice (Proceedings of the 30th annual conference of the Mathematics Education Research Group of Australasia, Tasmania, pp. 698-707). Adelaide: MERGA.

Sullivan, P., McDonough, A., \& Turner Harrison, R. (2004). Students' perceptions of factors contributing to successful participation in mathematics. In M. Johnsen Hoines \& A. Berit Fugelstad (Eds.), 28th conference of the International Group for the Psychology of Mathematics Education (Vol. 3, pp. 289-296). Bergen, Norway: Bergen University College.

Sullivan, P., Tobias, S., \& McDonough, A. (2006). Perhaps the decision of some students not to engage in learning mathematics in school is deliberate. Educational Studies in Mathematics, 62(1), 81-99. 
Taylor, M., Hawera, N., \& Young-Loveridge. (2005). Children's views of their teacher's role in helping them learn mathematics. In P. Clarkson, A. Downton, D. Gronn, M. Horne, A. McDonough, R. Pierce \& A. Roche (Eds.), Building connections: Research, theory and practice (Proceedings of the 28th annual conference of the Mathematics Education Group of Australasia, Melbourne, pp. 728734). Sydney: MERGA.

Walshaw, M. (2004a). Becoming knowledgeable in practice: The constitution of secondary teaching identity. In I. Putt, R. Faragher \& M. McLean (Eds.), Mathematics education for the third millennium: Towards 2010 (Proceedings of the 27th annual conference of the Mathematics Education Research Group of Australasia, Townsville, pp. 557-564). Sydney: MERGA, Inc.

Walshaw, M. (2004b). Pre-service mathematics teaching in the context of schools: An exploration into the constitution of identity. Journal of Mathematics Teacher Education, 7, 63-86.

Watson, J., Beswick, K., Brown, N., \& Callingham, R. (2007). Student change associated with teachers' professional learning. In J. Watson \& K. Beswick (Eds.), Mathematics: Essential research, essential practice (Proceedings of the 30th annual conference of the Mathematics Education Research Group of Australasia, Tasmania, pp. 785-795). Adelaide: MERGA.

Watt, H. M. G. (2005). Attitudes to the use of alternative assessment methods in mathematics: A study with secondary mathematics teachers in Sydney, Australia. Educational Studies in Mathematics, 58, 21-44.

Williams, G. (2006). Autonomous looking-in to support creative mathematical thinking: Capitilising on activity in Australian LPS classrooms. In D. Clarke, C. Kietel \& Shimizu (Eds.), Mathematics classrooms in twelve countries: The insider's perspective (pp. 221-236). Rotterdam, The Netherlands: Sense.

Wilson, S., \& Thornton, S. (2005). 'I am really not alone in this anxiety': Bibliotheraphy and pre-service primary teachers' self-image as mathematicians. In P. Clarkson, A. Downton, D. Gronn, M. Horne, A. McDonough, R. Pierce \& A. Roche (Eds.), Building connections: Research, theory and practice (Proceedings of the 28th annual conference of the Mathematics Education Group of Australasia, Melbourne, pp. 791-798). Sydney: MERGA.

Wilson, S., \& Thornton, S. (2006). To heal and enthuse: Developmental bibliotherapy and pre-service primary teachers' reflections on learning and teaching mathematics. In P. Grootenboer, R. Zevenbergen \& M. Chinnappan (Eds.), Identities, cultures and learning spaces (Proceedings of the 29th annual conference of the Mathematics Education Research Group of Australasia, Canberra, pp. 36-44). Adelaide: MERGA.

Young-Loveridge, J., \& Taylor, M. (2005). Children's views about mathematics learning after participation in a numeracy initiative. Research in Education, 74, 83-90.

Young-Loveridge, J., Taylor, M., Sharma, S., \& Hawera, N. (2006). Students' perspectives on the nature of mathematics. In P. Grootenboer, R. Zevenbergen \& M. Chinnappan (Eds.), Identities, cultures and learning spaces (Proceedings of the 29th annual conference of the Mathematics Education Research Group of Australasia, Canberra, pp. 583-590). Adelaide: MERGA.

Zan, R., Brown, L., Evans, J., \& Hannula, M. S. (2006). Affect in mathematics education: An introduction. Educational Studies in Mathematics, 63(2), 113-121.

Zevenbergen, R. (2006). Teacher identity from a bourdieuian perspective. In P. Grootenboer, R. Zevenbergen \& M. Chinnappan (Eds.), Identities, cultures and learning spaces (Proceedings of the 29th annual conference of the Mathematics Education Research Group of Australasia, Canberra, pp. 616-618). Adelaide: MERGA.

\section{AFFILIATIONS}

\section{Peter Grootenboer}

Gregor Lomas 
GROOTENBOER, LOMAS, \& INGRAM

Naomi Ingram 